\title{
A survey of clusterin and fascin expression in sarcomas and spindle cell neoplasms: strong clusterin immunostaining is highly specific for follicular dendritic cell tumor
}

\author{
Karen L Grogg, William R Macon, Paul J Kurtin and Antonio G Nascimento \\ Division of Anatomic Pathology, Department of Laboratory Medicine and Pathology, Mayo Clinic, Rochester, \\ MN, USA
}

\begin{abstract}
Clusterin, a glycoprotein implicated in many cellular functions including apoptosis, has recently been shown to be strongly expressed in follicular dendritic cell tumors, and to be absent or only weakly expressed in other dendritic cell tumors. Fascin has also been investigated as a potential marker of dendritic cell neoplasms. We evaluated staining for antibodies directed against these two antigens in 202 spindle cell tumors, including cases of follicular dendritic cell tumor $(n=14)$, interdigitating dendritic cell tumor $(n=7)$, leiomyosarcoma ( $n=17)$, inflammatory myofibroblastic tumor $(n=13)$, inflammatory pseudotumor $(n=2)$, spindle cell thymoma $(n=17)$, synovial sarcoma $(n=11)$, fibrosarcoma $(n=14)$, liposarcoma $(n=27)$, gastrointestinal stromal tumor $(n=13)$, malignant fibrous histiocytoma $(n=18)$, angiomatoid fibrous histiocytoma $(n=4)$, angiosarcoma $(n=10)$, malignant peripheral nerve sheath tumor $(n=8)$, malignant melanoma $(n=16)$, and spindle cell carcinoma $(n=11)$. Among these spindle cell neoplasms, strong diffuse clusterin staining had an overall specificity of $93 \%$ and a sensitivity of $100 \%$ for follicular dendritic cell tumor. Clusterin staining was least reliable in distinguishing follicular dendritic cell tumor from spindle cell thymoma or malignant fibrous histiocytoma, but these are entities that usually can be distinguished by clinical and morphologic data. Rare cases of leiomyosarcoma, fibrosarcoma and angiosarcoma may show strong clusterin staining. Fascin staining was very nonspecific among spindle cell tumors and thus does not imply a dendritic cell lineage.
\end{abstract}

Modern Pathology (2005) 18, 260-266, advance online publication, 1 October 2004; doi:10.1038/modpathol.3800294

Keywords: clusterin; fascin; follicular dendritic cell tumor; immunohistochemistry; sarcoma

Follicular dendritic cell tumors are rare spindle cell neoplasms that usually are identified as lymph node-based neoplasms, but can obscure the underlying lymph node or occur extranodally. ${ }^{1-3}$ As the histologic differential diagnosis includes other dendritic cell tumors as well as other sarcomas and spindle cell neoplasms, the diagnosis has required immunohistochemical positivity for CD21, CD23, and/or CD35. Our previous publication documented that addition of a clusterin stain to this immunohistochemical panel enhances its diagnostic sensitivity for follicular dendritic cell tumor. ${ }^{4}$

Correspondence: Dr KL Grogg, MD, Department of Laboratory Medicine and Pathology, 200 First Street SW, Rochester, MN 55905, USA.

E-mail: grogg.karen@mayo.edu

Presented in part at the 93rd Annual Meeting of the United States and Canadian Academy of Pathology, Vancouver, British Columbia, March 8, 2004.

Received 27 May 2004; revised 5 August 2004; accepted 6 August 2004; published online 1 October 2004
Fascin expression has also been proposed as a potential marker of dendritic cell neoplasms. ${ }^{5-7}$ The specificity of these markers among a variety of sarcomas and other spindle cell neoplasms has not been established.

Interest in clusterin as a diagnostic marker began when gene array analysis identified its expression in anaplastic large cell lymphoma. ${ }^{8}$ Since this report, it has been shown that $80-100 \%$ of systemic anaplastic large cell lymphomas and $40-60 \%$ of primary cutaneous anaplastic large cell lymphomas are immunohistochemically positive for clusterin., ${ }^{9,10}$ Additional immunohistochemical surveys among hematopoietic neoplasms have reported clusterin expression in a small subset $(12 \%)$ of diffuse large B-cell lymphomas and rarely in cases of peripheral T-cell lymphoma and nodular sclerosis Hodgkin's lymphoma. ${ }^{10,11}$ Among nonhematopoietic neoplasms, overexpression of clusterin has been documented in carcinomas of the breast, colon, pancreas and prostate. ${ }^{11-14}$ 
The initial immunohistochemical studies using antibodies to fascin documented its expression in Reed-Sternberg cells of classical Hodgkin's lymphoma, and suggested that this might be evidence of the dendritic lineage of these cells. ${ }^{6}$ While subsequent studies have shown that the neoplastic cells in Hodgkin's lymphoma are actually of B-cell lineage, the emphasis on fascin as a dendritic cell marker has remained. Indeed, it is expressed in the majority of follicular dendritic cell tumors, interdigitating dendritic cell tumors, and Langerhans cell histiocytoses. $^{2,5,15}$ The expression of fascin in other spindle cell tumors, however, has not been formally evaluated.

We collected 202 cases of a wide variety of sarcomas and spindle cell tumors from our files, with an emphasis on lesions that might enter the differential diagnosis of dendritic cell tumors. Immunohistochemical analysis of these cases was performed to determine the specificity of fascin and clusterin for dendritic cell neoplams.

\section{Materials and methods}

After Mayo Foundation Institutional Review Board approval had been obtained, formalin-fixed, paraffin-embedded blocks from a total of 202 previously diagnosed cases were retrieved from the Mayo Clinic archives. Data on 12 follicular dendritic cell tumors and six interdigitating dendritic cell tumors, including the histologic features of these cases, have been described in detail elsewhere. ${ }^{4}$ Two additional cases of follicular dendritic cell tumor (a CD35positive retroperitoneal mass and a CD21, CD23, CD35-positive peripancreatic mass) and one additional case of interdigitating dendritic cell tumor (an S100 positive lesion in a cervical lymph node) were included for a total of 14 and 7, respectively. The other cases included leiomyosarcoma $(n=17)$, inflammatory myofibroblastic tumor $(n=13)$, inflammatory pseudotumor $(n=2)$, spindle cell thymoma $(n=17)$, synovial sarcoma $(n=11)$, fibrosarcoma $(n=14)$, liposarcoma $(n=27)$, gastrointestinal stromal tumor $(n=13)$, malignant fibrous histiocytoma $(n=18)$, angiomatoid fibrous histiocytoma $(n=4)$, angiosarcoma $(n=10)$, malignant peripheral nerve sheath tumor $(n=8)$, desmoplastic $(n=10)$ or spindle cell $(n=6)$ malignant melanoma, and spindle cell carcinoma $(n=11)$. The diagnosis was verified in each case by histomorphologic review and confirmatory immunostains when necessary.

Cases of inflammatory myofibroblastic tumor included a histologic spectrum of lesions with variable degrees of fibrosis, mixed inflammatory cell infiltrate and spindle cell proliferation, and all were negative for the follicular dendritic cell markers CD21, CD23 and CD35. The inflammatory myofibroblastic tumors were from various locations including liver $(n=3)$, spleen $(n=1$, previously reported $\left.^{16}\right)$, lung $(n=2)$, small bowel mesentery $(n=3)$, pelvis $(n=2)$, kidney $(n=1)$, and spermatic cord $(n=1)$. Two cases considered as reactive/ reparative inflammatory pseudotumors were from the orbit $(n=1)$ and bladder $(n=1)$. Liposarcoma cases included well-differentiated sclerosing $(n=15)$, dedifferentiated $(n=5)$, myxoid/round cell $(n=3)$, and pleomorphic $(n=4)$ types. Spindle cell carcinoma cases were from the lung $(n=4)$, oropharynx $(n=2)$, kidney $(n=1)$, ureter $(n=1)$, skin $(n=1)$, breast $(n=1)$, and vulva $(n=1)$.

Each case was subjected to immunohistochemical staining with antibodies directed against fascin and clusterin (Table 1). Positivity for each antigen was scored both quantitatively (negative, $<50 \%$ or $>50 \%$ of cells staining) and qualitatively (weak, moderate, or strong staining).

\section{Results}

The immunohistochemical results are summarized in Table 2. The cases showing positive staining were divided into two categories. The category of focal and/or weak/moderate included cases with weak staining in 1-100\% of the cells as well as those with moderate staining in $<50 \%$ of the cells. The category of diffuse, moderate/strong included cases with moderate or strong staining in $>50 \%$ of the cells.

Diffuse moderate or strong clusterin staining was $100 \%$ sensitive for follicular dendritic cell tumor (Figure 1), and 93\% specific for follicular dendritic cell tumor among the sarcomas and spindle cell neoplasms studied. Although a minor subset of many sarcomas showed weak or focal moderate

Table 1 Antibodies applied to sarcomas and spindle cell tumors

\begin{tabular}{|c|c|c|c|c|}
\hline Antigen & $\begin{array}{l}\text { Antibody clone } \\
\text { (source) }\end{array}$ & Dilution & Pretreatment & Instrument \\
\hline Fascin & $\begin{array}{l}\text { 55K-2 (Dako, } \\
\text { Carpinteria, CA, USA) }\end{array}$ & $1: 500$ & EDTA HIER (30 min) & $\begin{array}{l}\text { TechMate (BioTek } \\
\text { Solutions, Santa } \\
\text { Barbara, CA, USA) }\end{array}$ \\
\hline Clusterin & $\begin{array}{l}\text { 41D (Upstate } \\
\text { Biotechnologies, Lake } \\
\text { Placid, NY, USA) }\end{array}$ & $1: 200$ & EDTA HIER (30 min) & $\begin{array}{l}\text { Ventana ES (Ventana } \\
\text { Medical Systems, } \\
\text { Tucson, AZ, USA) }\end{array}$ \\
\hline
\end{tabular}

HIER, heat-induced epitope retrieval. 
Table 2 Immunostaining results for fascin and clusterin in spindle cell tumors

\begin{tabular}{|c|c|c|c|c|}
\hline \multirow[t]{2}{*}{ Diagnosis $(N)$} & \multicolumn{2}{|c|}{ Fascin } & \multicolumn{2}{|c|}{ Clusterin } \\
\hline & Focal and/or w/m (\%) & Diffuse, $\mathrm{m} / \mathrm{s}(\%)$ & Focal and/or w/m (\%) & Diffuse, $\mathrm{m} / \mathrm{s}(\%)$ \\
\hline Follicular dendritic cell tumor (14) & $0(0)$ & $13(93)$ & $0(0)$ & $14(100)$ \\
\hline Interdigitating dendritic cell tumor (7) & $0(0)$ & $7(100)$ & $3(43)$ & $0(0)$ \\
\hline Well-differentiated liposarcoma (15) & $0(0)$ & $15(100)$ & $4(27)$ & $0(0)$ \\
\hline Dedifferentiated liposarcoma (5) & $0(0)$ & $5(100)$ & $1(20)$ & $0(0)$ \\
\hline Round cell liposarcoma (3) & $1(33)$ & $2(67)$ & $0(0)$ & $0(0)$ \\
\hline Pleomorphic liposarcoma (4) & $0(0)$ & $4(100)$ & $0(0)$ & $0(0)$ \\
\hline Leiomyosarcoma (17) & $7(41)$ & $4(24)$ & $7(41)$ & $1(6)$ \\
\hline Gastrointestinal stromal tumor (13) & $3(23)$ & $1(8)$ & $3(23)$ & $0(0)$ \\
\hline Malignant peripheral nerve sheath tumor (8) & $0(0)$ & $0(0)$ & $3(38)$ & $0(0)$ \\
\hline Synovial sarcoma (11) & $0(0)$ & $11(100)^{\mathrm{a}}$ & $4(36)^{\mathrm{a}}$ & $0(0)$ \\
\hline Fibrosarcoma (14) & $0(0)$ & $2(14)$ & $1(7)$ & $2(14)$ \\
\hline Inflammatory myofibroblastic tumor (13) & $2(15)$ & $4(31)$ & $1(8)$ & $0(0)$ \\
\hline Inflammatory pseudotumor (2) & $0(0)$ & $1(50)$ & $0(0)$ & $0(0)$ \\
\hline Spindle cell thymoma (17) & $6(35)$ & $7(41)$ & $5(29)$ & $5(29)$ \\
\hline Malignant fibrous histiocytoma (18) & $3(17)$ & $11(61)$ & $4(22)$ & $5(28)$ \\
\hline Angiomatoid fibrous histiocytoma (4) & $2(50)$ & $0(0)$ & $0(0)$ & $0(0)$ \\
\hline Angiosarcoma (10) & $0(0)$ & $10(100)$ & $3(30)$ & $1(10)$ \\
\hline Melanoma, spindle cell (6) & $0(0)$ & $5(83)$ & $2(33)$ & $0(0)$ \\
\hline Melanoma, desmoplastic (10) & $2(20)$ & $8(80)$ & $0(0)$ & $0(0)$ \\
\hline Spindle cell carcinoma (11) & $0(0)$ & $10(91)$ & $2(18)$ & $0(0)$ \\
\hline
\end{tabular}

w/m, weak to moderate staining; $\mathrm{m} / \mathrm{s}$, moderate or strong staining. The category of focal and/or weak/moderate includes cases with weak staining in $1-100 \%$ of the cells and those with moderate staining in $<50 \%$ of the cells. The category of diffuse, moderate/strong includes cases with moderate or strong staining in $>50 \%$ of the cells.

${ }^{\mathrm{a}}$ Similar staining was observed in both epithelioid and spindled components.

clusterin staining (Figure 2a), only rare cases of leiomyosarcoma $(n=1)$, angiosarcoma $(n=1)$ and fibrosarcoma $(n=2)$ showed strong diffuse staining (Table 2). These four cases were confirmed to be immunohistochemically negative for CD21, CD23 and CD35.

It was noted that areas of apoptotic/necrotic cells stained very strongly for clusterin even in tumors that did not express the protein in viable cells (Figure 2b). These areas were therefore not used to judge clusterin positivity. Care was also taken not to overinterpret background staining due to clusterin positivity in secretions or serum. Clusterin staining as a single tool was least reliable in distinguishing follicular dendritic cell tumors from spindle cell thymomas or malignant fibrous histiocytoma (Figure 3).

In contrast, fascin staining was quite nonspecific among sarcomas and spindle cell neoplasms (Figure 4). Diffuse, moderate or strong fascin staining was seen in the large majority of follicular dendritic cell tumors, interdigitating dendritic cell tumors, liposarcomas, synovial sarcomas, angiosarcomas, malignant melanomas, and spindle cell carcinomas, as well as in a significant subset of leiomyosarcomas, spindle cell thymomas, malignant fibrous histiocytomas and inflammatory myofibroblastic tumors.

\section{Discussion}

Our previous study indicated that strong clusterin staining is highly sensitive for follicular dendritic cell tumors, and that it also distinguishes follicular dendritic cell tumors from other dendritic cell neoplasms including interdigitating dendritic cell tumors and Langerhans cell histiocytoses. ${ }^{4}$ In this expanded immunohistochemical survey, we demonstrate that strong clusterin staining is $93 \%$ specific for follicular dendritic cell tumor among a variety of sarcomas and spindle cell neoplasms. In contrast, fascin staining is nonspecific among sarcomas and thus does not imply a dendritic cell lineage.

The reported findings indicate that a clusterin stain is a useful addition to an immunohistochemical panel in the evaluation of low-grade spindle cell neoplasms with features of follicular dendritic cell tumor, such as a whorling growth pattern and intimately admixed lymphocytes. Our previous study as well as others have documented that the traditional follicular dendritic cell markers CD21, CD23 and CD35 are sometimes limited by focality and variability in intensity of staining., ${ }^{47,18}$ In addition, clusterin appears to have greater sensitivity for follicular dendritic cell tumor compared to CD21, CD23 and CD35. In our practice, we have found that strong clusterin staining in $>50 \%$ of the cells is diagnostically useful in situations of morphologically unusual cases of FDCT that show positivity for CD21 or CD35, as well as in morphologically typical cases that lack expression of these antigens.

The clusterin glycoprotein is expressed in a variety of cell types, including the epithelial cells at most fluid-tissue boundaries, and appears to have diverse functions in the transport of lipoproteins, 

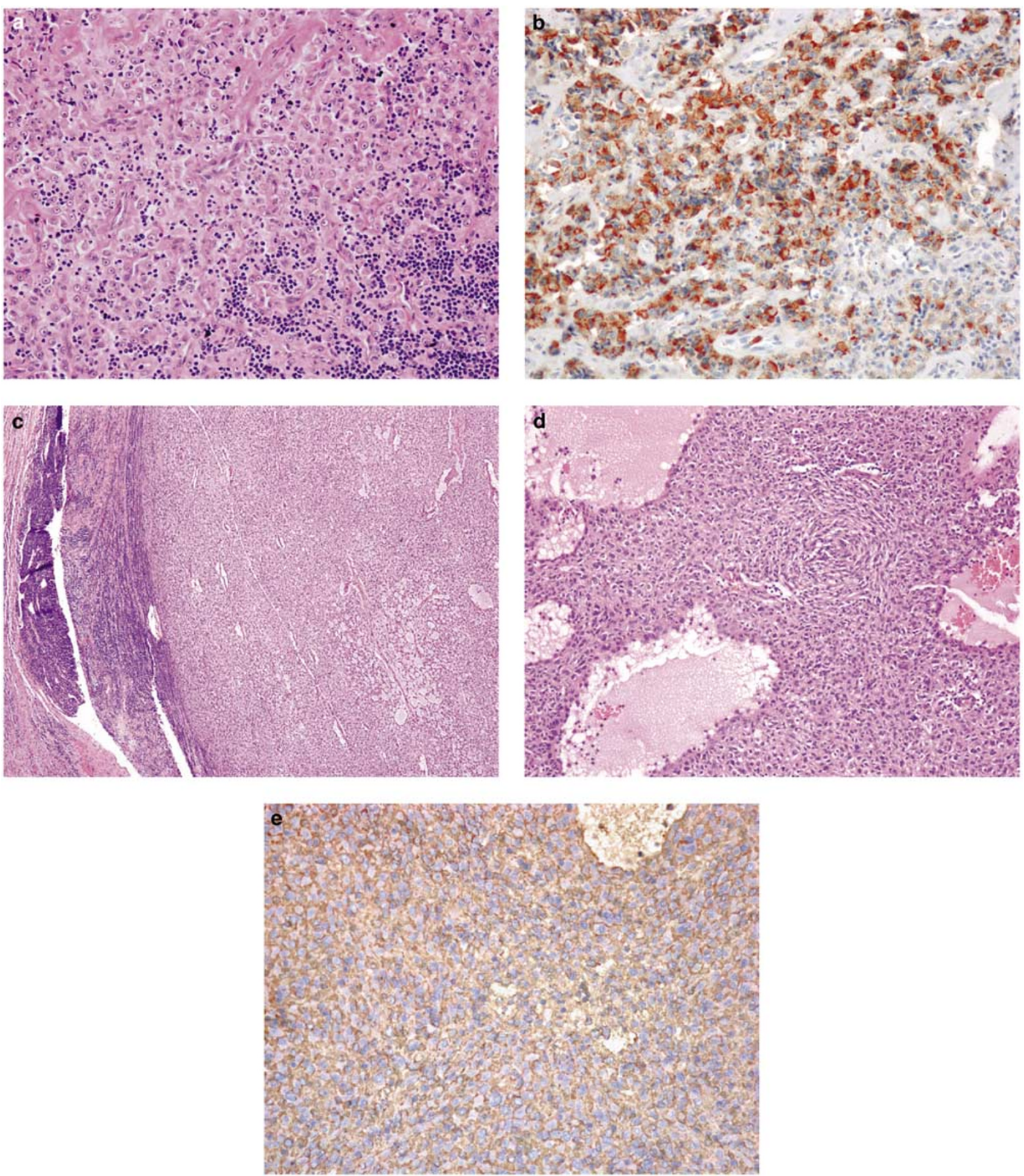

Figure 1 Strong clusterin staining was seen in all cases of follicular dendritic cell tumor. (a) This large retroperitoneal mass consisted of spindled to epithelioid cells, fibrosis and inflammatory cells, (b) and showed strong cytoplasmic and membranous positivity for clusterin. CD35 was focally positive (not shown). (c) This peripancreatic spindled and myxoid lesion appeared to arise within a lymph node (left), (d) showed a very focal whorling pattern and intermixed lymphocytes, and (e) showed strong cytoplasmic positivity for clusterin. CD21 and CD35 were also positive (not shown).

inhibition of complement-mediated cell lysis, and as a stress-induced secreted chaperone protein, which protects other secreted proteins from degradation. ${ }^{19}$ Initially, it was also implicated in the process of apoptotic cell death, but more recent studies have demonstrated that its enhanced expression in many apoptotic tissues is restricted to the vital neighboring cells, suggesting a cytoprotective 
264
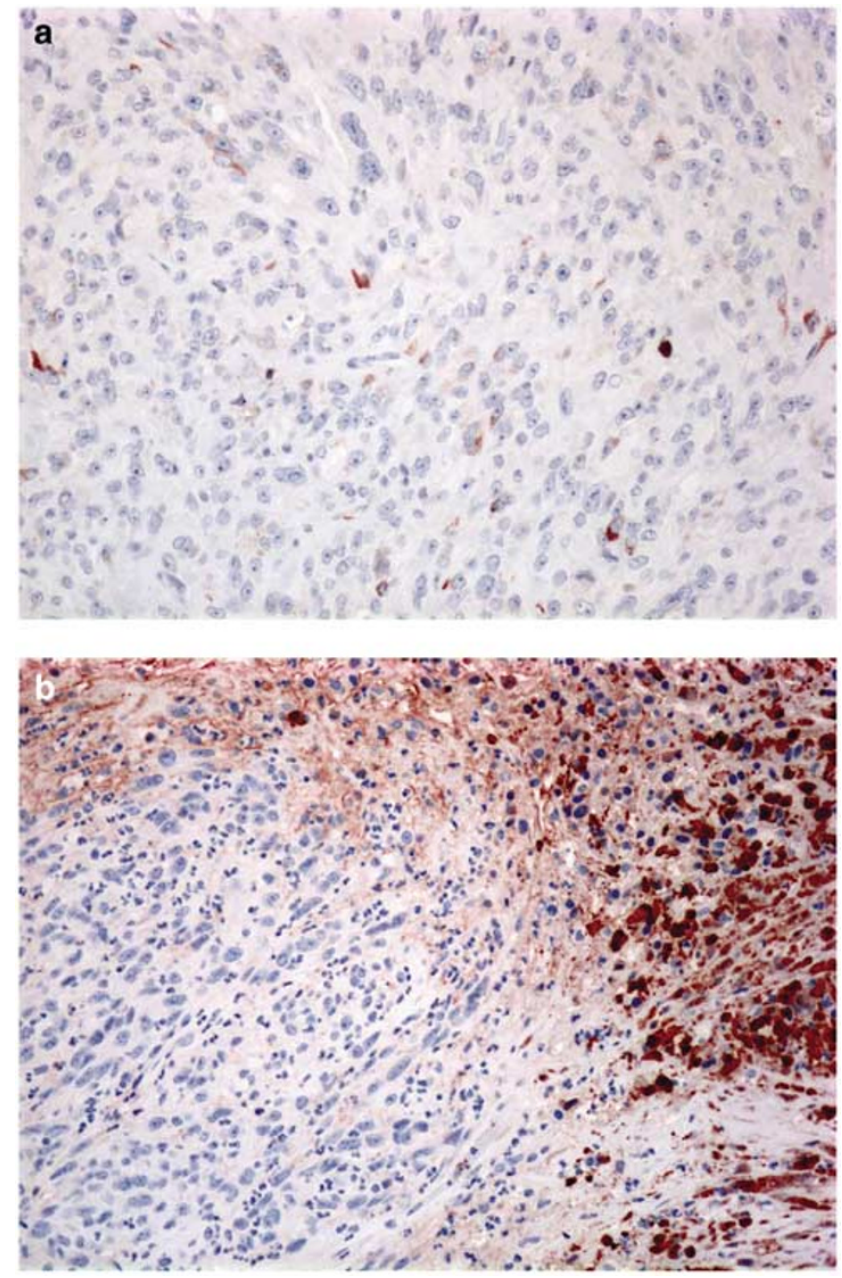

Figure 2 Strong clusterin staining was highly specific for follicular dendritic cell tumor. (a) The large majority of leiomyosarcomas were negative for clusterin, or as in this case showed at most moderate staining in $<50 \%$ of the cells. (b) This example of malignant melanoma showed spindled morphology and was negative for clusterin. However, strong clusterin staining was present in cells adjacent to areas of necrosis (upper right). Strong clusterin staining was a consistent observation in areas of necrosis, regardless of the degree of positivity in non-necrotic areas. Therefore, this should not be falsely interpreted as inherent positivity within the neoplasm.

role. ${ }^{19,20}$ Our observation that cells in areas of apoptosis or tumor necrosis showed strong clusterin staining by immunohistochemistry would be expected based on the apparent role of the protein in this process. It should be emphasized that enhanced clusterin expression was seen surrounding areas of necrosis even when the background tumor cells were negative, and these areas should be disregarded in terms of supportive evidence of follicular dendritic cell tumor. An additional potential pitfall in clusterin stain interpretation relates to its ubiquitous presence in serum and secretions. This occasionally resulted in increased background staining that should not be falsely interpreted as positivity within the neoplastic cells.
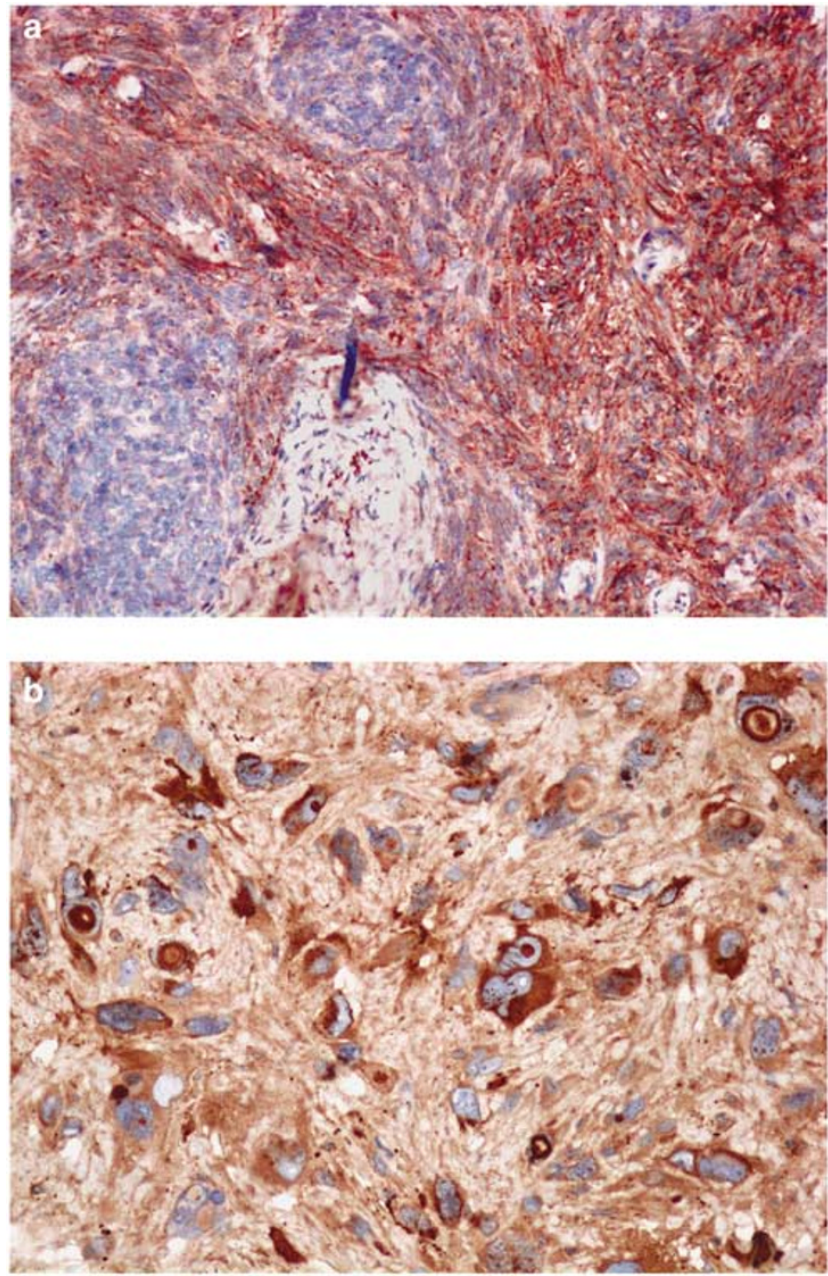

Figure 3 A subset of spindle cell thymomas and malignant fibrous histiocytomas showed strong clusterin staining. (a) Only the spindled component of this mixed thymoma showed strong clusterin staining. (b) The pleomorphic cells of this malignant fibrous histiocytomas showed strong clusterin staining.

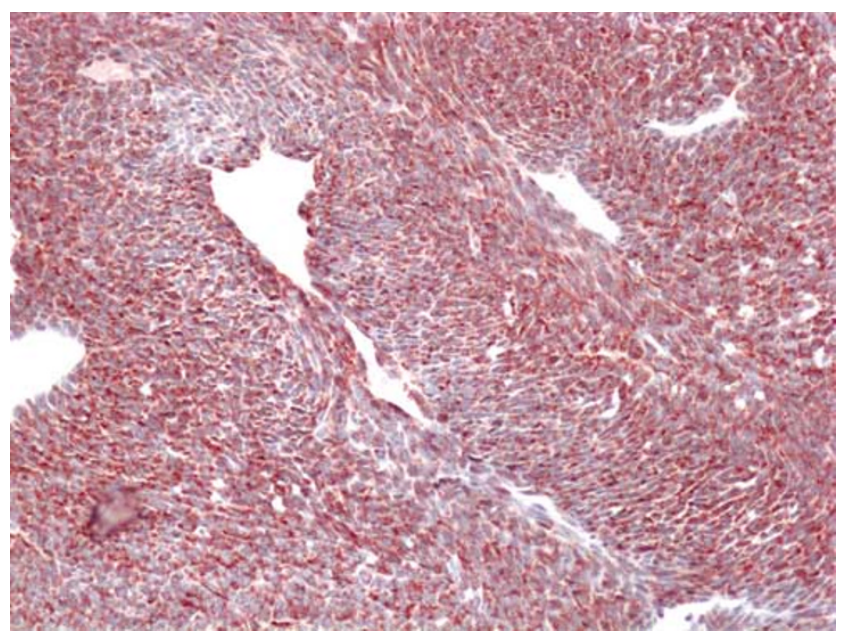

Figure 4 Fascin staining was not specific for dendritic cell neoplasms but stained the majority of a wide range of spindle cell neoplasms. This image illustrates the strong, diffuse fascin staining seen in all synovial sarcomas evaluated. 
Given the expression of clusterin in a wide variety of benign epithelial cells as well as in carcinomas of the breast, colon, pancreas, ovary, bladder and prostate, ${ }^{11-14}$ it is somewhat surprising that we did not observe strong clusterin staining in any of 11 spindle cell carcinomas. Our case selection was somewhat limited in its scope with the majority representing spindle cell squamous carcinomas from various locations. We can therefore not exclude the possibility that a subset of spindle cell carcinomas could show strong clusterin expression.

Clusterin staining was least reliable in distinguishing follicular dendritic cell tumors from malignant fibrous histiocytoma and spindle cell thymoma. Generally, this is a differential diagnosis that can be resolved with correlation of all clinicopathologic features. Follicular dendritic cell tumors can show pleomorphic cytology similar to malignant fibrous histiocytoma, as was observed in two of the 14 follicular dendritic cell tumors in this series (described in detail in the previous publication ${ }^{4}$ ). In these cases, a search for areas more typical of follicular dendritic cell tumors and stains for CD21, CD23 and CD35 can help separate these entities since a clusterin stain alone is not a reliable discriminant.

Spindle cell (medullary) thymoma can be distinguished from follicular dendritic cell tumor by cytokeratin positivity and an anterior mediastinal location. In situ hybridization studies have localized expression of clusterin mRNA to thymic medullary epithelial cells, ${ }^{21}$ and our immunohistochemical studies confirm this in neoplastic thymic epithelium. Spindle cell thymomas share many histologic features with follicular dendritic cell tumors, including nodules or whorls of spindled cells with vesicular nuclei, perivascular spaces, and intermixed lymphocytes. The strong expression of clusterin may suggest that medullary cells of the thymus also have physiologic similarities to follicular dendritic cells. The interaction of follicular dendritic cells with activated, antigen-specific B cells serves to rescue them from apoptosis and promote the development of memory B cells. ${ }^{22}$ Given its purported cytoprotective role, the secreted clusterin protein may be involved in this process. It is plausible that clusterin may serve a similar role in the interaction between thymic medullary epithelial cells and immature $\mathrm{T}$ cells.

In contrast to the specificity of strong clusterin staining, fascin staining was found in the majority of spindle cell tumors included in the study. Therefore, it does not provide evidence of dendritic cell lineage, as has been suggested.

In conclusion, we have demonstrated that clusterin immunostaining is of significant utility in the diagnostic evaluation of sarcomas and spindle cell neoplasms. Diffuse, strong clusterin staining showed $100 \%$ sensitivity and $93 \%$ specificity for follicular dendritic cell tumor, and therefore is a useful supplemental marker to identify this neoplasm. Fascin staining does not appear to have a role in the diagnosis of spindle cell neoplasms.

\section{References}

1 Biddle DA, Ro JY, Yoon GS, et al. Extranodal follicular dendritic cell sarcoma of the head and neck region: three new cases, with a review of the literature. Mod Pathol 2002;15:50-58.

2 Weiss LM, Grogan TM, Muller-Hermelink H-K, et al. WHO classification of histiocytic and dendritic cell neoplasms. In: Jaffe ES, Harris NL, Stein H, Vardiman JW (eds). World Health Organization Classification of Tumours. Pathology and Genetics of Tumours of Haematopoietic and Lymphoid Tissues. IARC Press: Lyon, France, 2001, pp 274-289.

3 Perez-Ordonez B, Rosai J. Follicular dendritic cell tumor: review of the entity. Semin Diagn Pathol 1998; 15:144-154.

4 Grogg KL, Lae ME, Kurtin PJ, et al. Clusterin expression distinguishes follicular dendritic cell tumors from other dendritic cell neoplasms: report of a novel follicular dendritic cell marker and clinicopathologic data on 12 additional follicular dendritic cell tumors and 6 additional interdigitating dendritic cell tumors. Am J Surg Pathol 2004;28:988-998.

5 Pinkus GS, Lones MA, Matsumura F, et al. Langerhans cell histiocytosis immunohistochemical expression of fascin, a dendritic cell marker. Am J Clin Pathol 2002; 118:335-343.

6 Pinkus GS, Pinkus JL, Langhoff E, et al. Fascin, a sensitive new marker for Reed-Sternberg cells of Hodgkin's disease: evidence for a dendritic or B cell derivation? Am J Pathol 1997;150:543-562.

7 Pantanowitz L, Antonioli DA, Pinkus GS, et al. Inflammatory fibroid polyps of the gastrointestinal tract: evidence for a dendritic cell origin. Am J Surg Pathol 2004;28:107-114.

8 Wellman A, Thieblemont C, Pittaluga S, et al. Detection of differentially expressed genes in lymphomas using cDNA arrays: identification of clusterin as a new diagnostic marker for anaplastic large cell lymphomas. Blood 2000;96:398-404.

9 Lae ME, Ahmed I, Macon WR. Clusterin is widely expressed in systemic anaplastic large cell lymphoma but fails to differentiate primary from secondary cutaneous anaplastic large cell lymphoma. Am J Clin Pathol 2002;118:773-779.

10 Saffer H, Wahed A, Rassidakis GZ, et al. Clusterin expression in malignant lymphomas: a survey of 266 cases. Mod Pathol 2002;15:1221-1226.

11 Nascimento AF, Pinkus JL, Pinkus GS. Clusterin, a marker for anaplastic large cell lymphoma: immunohistochemical profile in hematopoietic and non-hematopoietic malignancies. Am J Clin Pathol 2004;121: 709-717.

12 July LV, Akbari M, Zellweger $\mathrm{T}$, et al. Clusterin expression is significantly enhanced in prostate cancer cells following androgen withdrawal therapy. Prostate 2002;50:179-188.

13 Redondo M, Villar E, Torres-Munoz J, et al. Overexpression of clusterin in human breast carcinoma. Am J Pathol 2000;157:393-399. 
14 Xie MJ, Motoo Y, Su SB, et al. Expression of clusterin in human pancreatic cancer. Pancreas 2002;25:234-238.

15 Perez-Ordonez B, Erlandson RA, Rosai J. Follicular dendritic cell tumor: report of 13 additional cases of a distinctive entity. Am J Surg Pathol 1996;20:944-955.

16 Lewis JT, Gaffney RL, Casey MB, et al. Inflammatory pseudotumor of the spleen associated with a clonal Epstein-Barr virus genome. Am J Clin Pathol 2003; 120:56-61.

17 Chan JKC, Fletcher CD, Nayler SJ, et al. Follicular dendritic cell sarcoma: clinicopathologic analysis of 17 cases suggesting a malignant potential higher than currently recognized. Cancer 1997;79:294-313.

18 Cheuk W, Chan JKC, Shek TWH, et al. Inflammatory pseudotumor-like follicular dendritic cell tumor.
A distinctive low-grade malignant intra-abdominal neoplasm with consistent Epstein-Barr virus association. Am J Surg Pathol 2001;25:721-731.

19 Jones SE, Jomary C. Clusterin. Int J Biochem Cell Biol 2002;34:427-431.

20 Koch-Brandt C, Morgans C. Clusterin: a role in cell survival in the face of apoptosis? Prog Mol Subcell Biol 1996;16:130-149.

21 French LE, Sappino AP, Tschopp J, et al. Distinct sites of production and deposition of the putative cell death marker clusterin in the human thymus. J Clin Invest 1992;90:1919-1925.

22 Nielsen CH, Fischer EM, Leslie RGQ. The role of complement in the acquired immune response. Immunology 2000;100:4-12. 